\title{
Cortex Fraxini (Qingpi) Protects Rat Pheochromocytoma Cells against 6-Hydroxydopamine-Induced Apoptosis
}

\author{
Jing-Jie Li, ${ }^{1,2}$ Shi-Ya Zhou, ${ }^{2}$ Huan Zhang, ${ }_{1,3}^{1,3}$ Kim-Hung Lam, ${ }^{1}$ Simon Ming-Yuen Lee, ${ }^{4}$ \\ Peter Hoi-Fu Yu, ${ }^{1,5}$ and Shun-Wan Chan ${ }^{1,3,6}$ \\ ${ }^{1}$ Department of Applied Biology and Chemical Technology, The Hong Kong Polytechnic University, Hong Kong \\ ${ }^{2}$ School of Biological Sciences, The University of Hong Kong, Hong Kong \\ ${ }^{3}$ Food Safety and Technology Research Centre, Department of Applied Biology and Chemical Technology, \\ The Hong Kong Polytechnic University, Hong Kong \\ ${ }^{4}$ State Key Laboratory of Quality Research in Chinese Medicine and Institute of Chinese Medical Sciences, University of Macau, \\ Avenue Padre Tomás Pereira S.J., Taipa, Macau \\ ${ }^{5}$ Faculty of Science and Technology, Technological and Higher Education Institute of Hong Kong, Hong Kong \\ ${ }^{6}$ State Key Laboratory of Chinese Medicine and Molecular Pharmacology, Shenzhen, China
}

Correspondence should be addressed to Shun-Wan Chan; bcswchan@polyu.edu.hk

Received 31 July 2014; Revised 16 September 2014; Accepted 16 September 2014

Academic Editor: Tauheed Ishrat

Copyright (C) 2015 Jing-Jie Li et al. This is an open access article distributed under the Creative Commons Attribution License, which permits unrestricted use, distribution, and reproduction in any medium, provided the original work is properly cited.

\begin{abstract}
Parkinson's disease (PD) is a chronic neurodegenerative disorder having close relationship with oxidative stress induced by reactive oxygen species (ROS). Cortex Fraxini (QP) is a kind of traditional Chinese medicinal herb with antioxidant properties. It may be a potential candidate for preventing the development of chronic neurodegenerative diseases. Thus, the key objective of the current study was to investigate the neuroprotective effect of QP water extract on 6-hydroxydopamine (6-OHDA) induced apoptosis in rat pheochromocytoma (PC12) cells. It was found that $\mathrm{QP}$ water extract possesses strong antioxidant property with $\mathrm{SC}_{50}=$ $0.15 \mathrm{mg} / \mathrm{mL}$. Total phenolic content of QP water extract was found to be $200.78 \pm 2.65 \mathrm{mg}$ GAE/g. QP water extract's free radical scavenging capacity was demonstrated by reversing the increased level of intracellular ROS induced by 6 -OHDA, using $2^{\prime}, 7^{\prime}$ dichlorodihydrofluorescein diacetate. Moreover, QP water extract $(0.5 \mathrm{mg} / \mathrm{mL})$ could remarkably increase the viability of PC12 cells treated with 6-OHDA. The protective effect of QP water extract was found to be via inhibiting MEK/ERK pathway and reversing PI3-K/Akt/GSK3 $\beta$ pathway. The current results suggest that QP might be a potential candidate for preventing the development of neurodegenerative diseases, such as PD.
\end{abstract}

\section{Introduction}

Parkinson's disease (PD), which frequently occurs among elderly especially those beyond 65 , is a chronic neurological disorder with some typical characteristic symptoms such as tremor, myotonia, and dyskinesia [1]. The pathophysiology of PD has not been thoroughly understood except some evidence showing that PD may be partly caused by nigral cell death [2].

6-Hydroxydopamine (6-OHDA), a neurotoxin, is mainly exerted neurotoxicity through two pathways including producing free radicals or blocking the mitochondrial respiratory chain [3]. Both pathways would lead to the formation of reactive species of oxygen (ROS) and increase of oxidative stress, which would interact with intercellular molecules (DNA, proteins, and lipid) and finally lead to neurotoxicity, including the loss of dopaminergic neurons in the substantia of nigra [4]. 6-OHDA can be transported into neurons by plasma membrane dopamine transporters and inhibits the mitochondrial electron transport chain complexes I and IV, resulting in ROS-induced neuronal damage as observed in PD $[5,6]$. Therefore, 6-OHDA is thought to induce toxicity, that is similar to the biochemical and neuropathological conditions in $\mathrm{PD}$, and commonly used either in vitro or in vivo to mimic $\mathrm{PD}[6]$. 
Cotex Fraxini (QP), a traditional Chinese herb, is the dried bark of Fraxinus rhynchophylla Hance, Fraxinus chinensis Roxb., Fraxinus chinensis Roxb. var. acuminate Lingelsh., and Fraxinus stylosa Lingelsh. usually from Jilin, Liaoning, and Hebei in China. It is a well-known herb belonging to the "heat-clearing" category in the classification of traditional Chinese medicine (TCM) [7] and frequently utilized to cure diarrhea, bacillary dysentery, arthritis, and hyperuricemia [8]. QP was found to possess abundant antioxidant constituents including phenolic acid and coumarins [9]. Therefore, it may have the potential to protect neuronal cells from ROS damage and prevent the development of neurodegenerative diseases. As a result, the aims of the current study were to investigate the antioxidant property of QP water extract and to evaluate the neuroprotective effect of QP water extract in 6OHDA-induced apoptosis in rat pheochromocytoma (PC12) cells. This in vitro model could mimic the oxidative stress induced cell death in PD [10]. Further mechanistic study was performed to unveil the antiapoptotic role of QP water extract in 6-OHDA-induced apoptosis in PC12 cells.

\section{Materials and Methods}

2.1. Chemicals and Reagents. Dulbecco's modified Eagle's medium (DMEM), fetal bovine serum (FBS), phosphate buffer saline (PBS), Horse serum (HS), antibiotics and antimycotics, trypsin 3-(4,5-dimethylthiazol-2-yl)-2,5-diphenyltetrazolium bromide (MTT) and Hoechst 33342 were purchased from Invitrogen (Carlsbad, CA, USA). PD98059, SB415286, and LY294002 were obtained from LC laboratories (Woburn, MA, USA). ECL plus kit were purchased from Amersham Bioscience (Aylesbury, UK). $2^{\prime}$, $7^{\prime}$-Dichlorodihydrofluorescein diacetate (DCFH-DA), ethyl alcohol (absolute ethanol), and dimethyl sulfoxide (DMSO) were purchased from Sigma-Aldrich Inc. (St. Louis, MO, USA). Cell lysis buffer, antibodies against phospho-MEK 1/2, phospho-ERK 1/2, ERK, phospho-PI3K, phospho-Akt, Akt, phospho-GSK3 $\beta$, GSK3 $\beta$ were obtained from Cell Signaling Technology (Beverly, MA, USA). Antibody against $\beta$-actin was obtained from Santa Cruz Biotechnology (Santa Cruz, CA, USA). All other chemicals used were of analytical grade.

2.2. Medicinal Herb Extract. QP was purchased from Chinese pharmacy in Hong Kong, China. $50 \mathrm{~g}$ of QP was weighed and put into $300 \mathrm{~mL}$ boiling distilled water for $1.5 \mathrm{~h}$ to extract its water-soluble substances. Given that the residues still contain part of substance which cannot be extracted in one time, the reextraction was performed with $300 \mathrm{~mL}$ boiling ultrafiltered water for another two times. QP water extract was then centrifuged at 5,000 rpm for $15 \mathrm{~min}$ to obtain a clear supernatant for freeze-drying at $-40^{\circ} \mathrm{C}$ for $48-72 \mathrm{~h}$ to acquire dry powder. The freeze-dried powder was kept at $-20^{\circ} \mathrm{C}$ before use. QP freeze-dried powder (QP water extract) was redissolved in water or culture medium to prepare solutions with various concentrations for different experiments. ysis on QP Water Extract. HPLC analysis was performed using an Agilent 1100 HPLC system (Milford, MA, USA) coupled to a photodiode array detector. The samples were separated on a Supelcosil LC-18 column $(250 \mathrm{~mm} \times 4.6 \mathrm{~mm}$; $5 \mu \mathrm{m}$ ) (Supelco, Bellefonte, PA, USA) and eluted at a flow rate of $1 \mathrm{~mL} / \mathrm{min}$ at $25^{\circ} \mathrm{C}$. The solvent system consisted of methanol-water-glacial acetic acid (30:70:4, v/v/v), and the detection wavelength was set at $348 \mathrm{~nm}$. QP water extract sample was dissolved in distilled water and filtered by a $0.45 \mu \mathrm{m}$ filter before HPLC analysis. The injection volume was $5 \mu \mathrm{L}$.

2.4. Cell Culture and Treatment. The PC12 cells were obtained from ATCC (Manassa, VA, USA) and cultured in DMEM supplemented with $10 \% \mathrm{FBS}, 1 \% \mathrm{HS}$, penicillin $(100 \mathrm{U} / \mathrm{mL})$, and streptomycin $(100 \mu \mathrm{g} / \mathrm{mL})$ in a humidified atmosphere of $95 \%$ air and $5 \% \mathrm{CO}_{2}$ at $37^{\circ} \mathrm{C}$. For the experiments with 6 OHDA, PC12 cells in DMEM with low serum content $(2 \%$ FBS and 1\% HS) were seed in 6-well plate or 96-well plate. PC12 cells were pretreated with QP water extract at various concentrations for $2 \mathrm{~h}$, before exposure to 6-OHDA for $4 \mathrm{~h}$.

2.5. Determination of Antioxidant Properties. In order to measure the antioxidant properties of QP water extract, DPPH free radical scavenging activity assay and total phenolic quantification are induced in this study. For DPPH assay, various concentrations of $\mathrm{QP}$ water extract and vitamin $\mathrm{C}$ were prepared by dissolving the dried powder with distilled water. $50 \mu \mathrm{L}$ of sample solution was added to $950 \mu \mathrm{L}$ of $\mathrm{DPPH}^{\bullet}$ methanol solution $(24 \mathrm{mg} / \mathrm{L})$ and allowed to react for $1 \mathrm{~h}$. The scavenging activity of each sample was measured by spectroscopic method. Absorbance of sample ( $\left.A_{\text {sample }}\right)$ was determined by UV-visible spectrometer (Perkin Elemer Lambda 35) at $515 \mathrm{~nm}$. Using $50 \mu \mathrm{L}$ of water as control $\left(A_{\text {control }}\right)$, the free radical scavenging rate $(\mathrm{SR} \%)$ of each concentration was calculated by the following equation:

$$
\mathrm{SR} \%=\left(1-\frac{A_{\text {sample }}}{A_{\text {control }}}\right) \times 100 \% .
$$

$A_{\text {control }}$ is absorbance value of $\mathrm{DPPH}^{\bullet}$ solution with $50 \mu \mathrm{L}$ of water.

$A_{\text {sample }}$ is absorbance value of $\mathrm{DPPH}^{\bullet}$ solution with $50 \mu \mathrm{L}$ of herbal extract.

The $50 \%$ scavenging concentration $\left(\mathrm{SC}_{50}\right)$ was calculated by GraphPad Prism 5.01 for Windows (GraphPad Software, San Diego California, USA).

For the determination of total phenolic content of QP water extract, Folin-Ciocalteu method was used to measure the total phenolic quantification of QP water extract, following the procedures we described before [11]. $100 \mu \mathrm{L}$ of sample solutions (QP water extract $(0.3,0.5$ and $1.0 \mathrm{mg} / \mathrm{mL})$ and gallic acid (0.01, 0.02, 0.03, 0.04, 0.05, 0.06, 0.07, and $0.08 \mathrm{mg} / \mathrm{mL})$ ) were mixed with $400 \mu \mathrm{L}$ of $\mathrm{Na}_{2} \mathrm{CO}_{3}(75.05 \mathrm{~g} / \mathrm{L})$ and $500 \mu \mathrm{L}$ of Folin-Ciocalteu reagent (1:10 diluted with water). The mixtures were then placed at room temperature for $2 \mathrm{~h}$ to allow reaction to take place. Absorbance of samples at $750 \mathrm{~nm}$ was determined by UV-visible spectrometer 
(Perkin Elemer Lambda 35). A standard curve was prepared by using different concentrations of freshly prepared gallic acid solutions. Total phenolic contents of the herbs were expressed as gallic acid equivalents (mg GAE/g).

2.6. Measurement of Cell Viability. After treatment with different stimuli, the medium was removed and replaced with the medium $(100 \mu \mathrm{L} /$ well $)$, adding with MTT solution $\left(5 \mathrm{mg} / \mathrm{mL}\right.$ in PBS). After $4 \mathrm{~h}$ incubation at $37^{\circ} \mathrm{C}$, the cell supernatants were discarded and $100 \mu \mathrm{L}$ DMSO was used to dissolve MTT crystals. The absorbance of the samples was then measured at a wavelength of $570 \mathrm{~nm}$ with $655 \mathrm{~nm}$ as a reference wavelength. All assays were performed in triplicate.

2.7. Determination of Intracellular ROS Level. To evaluate the production of intracellular ROS with the treatment of 6OHDA and QP water extract, $2^{\prime}, 7^{\prime}$-dichlorodihydrofluorescein diacetate (DCFH-DA) is used in the study based on the fact that intracellular deacetylation and oxidation of DCFHDA to $2^{\prime}, 7^{\prime}$-dichlorodihydrofluorescein (DCF), which is highly fluorescent [12].

PC12 cells were seeded in black 96-well plates at a density of $1.5 \times 104$ cells per well and grown at $37^{\circ} \mathrm{C}$ for 24 hours, and then DCFH-DA $(20 \mu \mathrm{M})$ was added for $1 \mathrm{~h}$ pretreatment. After changing the medium, the cells were pretreated with Qinpi $(0.5 \mathrm{mg} / \mathrm{mL})$ for 2 hours and then the medium was replaced with no phenol red DMEM before $500 \mu \mathrm{M}$ 6OHDA being added. The florescent intensity of DCF was scanned with a plate reader (Wallac; PerkinElmer) at $485 \mathrm{~nm}$ excitation and $535 \mathrm{~nm}$ emission. The results were expressed as folds increase of control.

2.8. Nuclear Staining for Assessment of Apoptosis. Hoechst staining assay is used to detect the change in morphology after exposing to 6-OHDA. Hoechst 33342 is the most commonly used cell-permanent nuclear counter stain that emits blue fluorescence to distinguish condensed pyknotic nuclei in apoptotic cells. After pretreating PC12 cells with $0.5 \mathrm{mg} / \mathrm{mL} \mathrm{QP}$ water extract for $2 \mathrm{~h}$ and incubation with $500 \mu \mathrm{M} 6$-OHDA for $2 \mathrm{~h}$ in a 12 -well plate $\left(2 \times 10^{6}\right.$ cells/well $)$, the medium was removed and all the wells were washed by ice-cold PBS. Cells were then stained by Hoechst 33342 $(5 \mu \mathrm{g} / \mathrm{mL})$ for $5 \mathrm{~min}$ at $4^{\circ} \mathrm{C}$. Nuclei could be observed using a fluorescence microscope at 400x magnification.

2.9. Flow Cytometry Analysis of Apoptosis. Apoptosis in PC12 cells was analyzed through the measurement of mitochondrial membrane potential quantification by flow cytometry using JC-1 dye (Molecular Probes). After incubation with 6OHDA, CCCP (carbonyl cyanide m-chlorophenylhydrazone, positive control) and QP water extract, PC12 cells were collected and centrifuged at $1200 \mathrm{rpm}$ for $5 \mathrm{~min}$. Removing the supernatants, the cell pellets were washed twice and resuspended in $500 \mu \mathrm{L}$ cold PBS. Then the cell suspension was transferred to $1.5 \mathrm{~mL}$ microcentrifuge tubes and centrifuged at $1200 \mathrm{rpm}$ for $3 \mathrm{~min}$. Aspirating the supernatant, cell pellets were resuspended in $500 \mu \mathrm{L}$ warm PBS. Then, $4 \mathrm{mM}$ JC-1 dye was added to each sample to make the final concentration as
$15 \mu \mathrm{M}$ before incubation at $37^{\circ} \mathrm{C}$ for $20 \mathrm{~min}$. The proportion of aggregated versus monomeric JC- 1 probe was quantified using the ratio of fluorescence emissions at $590 \mathrm{~nm}$ (red) over $530 \mathrm{~nm}$ (green) with a FACSCalibur flow cytometer. Consequently, the mitochondrial depolarization, which means the loss in mitochondrial membrane potential, is indicated by a decrease in the red/green fluorescence intensity ratio.

2.10. Western Blot Assay. Briefly, cells were collected after incubation in 6-well plate, using cell lysis buffer with $1 \mathrm{mM}$ PMSF. After incubation on ice for $10 \mathrm{~min}$ and centrifugation at $14,000 \mathrm{rpm}$ at $4^{\circ} \mathrm{C}$ for $15 \mathrm{~min}$, the whole protein concentrations were determined by the BCA assay (Pierce, Rockford, IL, USA) using bovine serum albumin as standard, after which cell protein was diluted in the SDS sample buffer, and the mixture was boiled for $5 \mathrm{~min}$. The protein $(30 \mu \mathrm{g})$ was separated on a $10 \%$ SDS-polyacrylamide gel. Then, the signals were transferred onto a polyvinyl difluoride membrane. Using $5 \%$ milk for $1 \mathrm{~h}$, the signals were blocked on the membrane and detected with primary antibodies. After incubation overnight at $4^{\circ} \mathrm{C}$, signals were obtained by binding a secondary antibody. The membrane was visualized using an ECL plus kit before exposure to FujiFilm autoradiographic films according to the manufacturer's protocol.

2.11. Statistics Analysis. All data are expressed as means \pm SEM. Differences in the mean among groups were assessed for significance by one-way ANOVA combined with the Bonferroni's test. Differences were considered significant when $P<0.05$. All statistical analysis tests were performed by GraphPad Prism 5.01 for Windows.

\section{Results}

3.1. HPLC Analysis. In order to ensure the quality consistency and standardization of the sample tested, the chemical characteristics of the QP water extract were determined using the HPLC-UV method. Representative HPLC chromatograms of mixed standards and QP extract were shown in Figure 1. The QP water extract (9.8 mg) was found to contain exculin hydrate $(1639.7 \pm 363.1 \mu \mathrm{g})$, fraxin $(1355.3 \pm 197.4 \mu \mathrm{g})$, esculetin $(163.4 \pm 11.8 \mu \mathrm{g})$, and flaxetin $(33.3 \pm 6.0 \mu \mathrm{g})$.

3.2. Determination of Antioxidant Properties. For DPPH assay, as is shown in Figure 2, QP water extract exerted a concentration-dependent scavenging activity against $\mathrm{DPPH}$ free radicals with $\mathrm{SC}_{50}$ of $0.15 \mathrm{mg} / \mathrm{mL}$ compared with that of ascorbic acid (Vitamin C, a positive control), which is $0.0030 \mathrm{mg} / \mathrm{mL}$. In addition, the total phenolic content of QP water extract was found to $200.78 \pm 2.65 \mathrm{mg} \mathrm{GAE} / \mathrm{g}$ dry extract.

3.3. QP Water Extract Attenuates 6-OHDA-Induced Cell Death in PC12 Cells. To analyze the cell injury induced by 6-OHDA, PC12 cells were exposed to 6-OHDA for $6 \mathrm{~h}$ with different concentrations ranging from 0 to $700 \mu \mathrm{M}$. As shown in Figure 3(a), the viability of the cells treated with 6-OHDA of $400,500,600$, and $700 \mu \mathrm{M}$ decreased significantly as compared with the control group (all with $P<0.001$ ). 


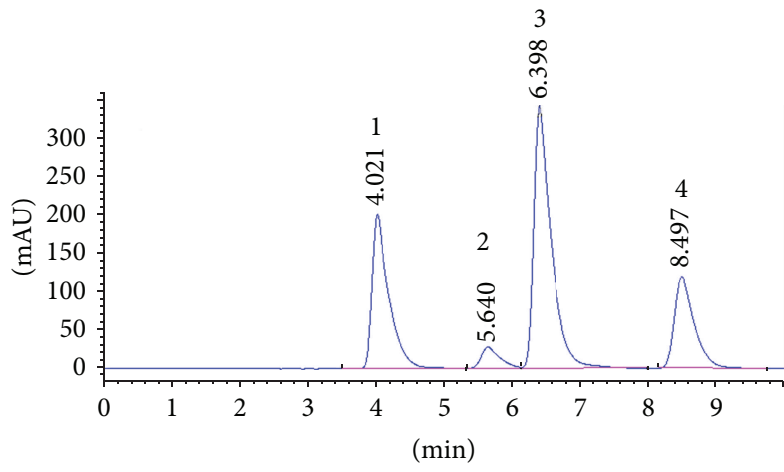

(a)

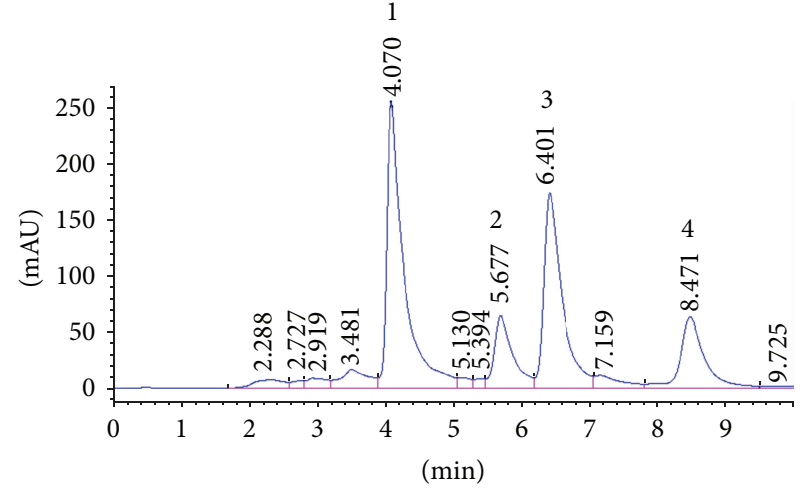

(b)

FIgURE 1: Representative HPLC-UV chromatograms of (a) mixed standards and (b) QP extract. Peaks: 1 is exculin hydrate, 2 is fraxin, 3 is esculetin, and 4 is flaxetin.

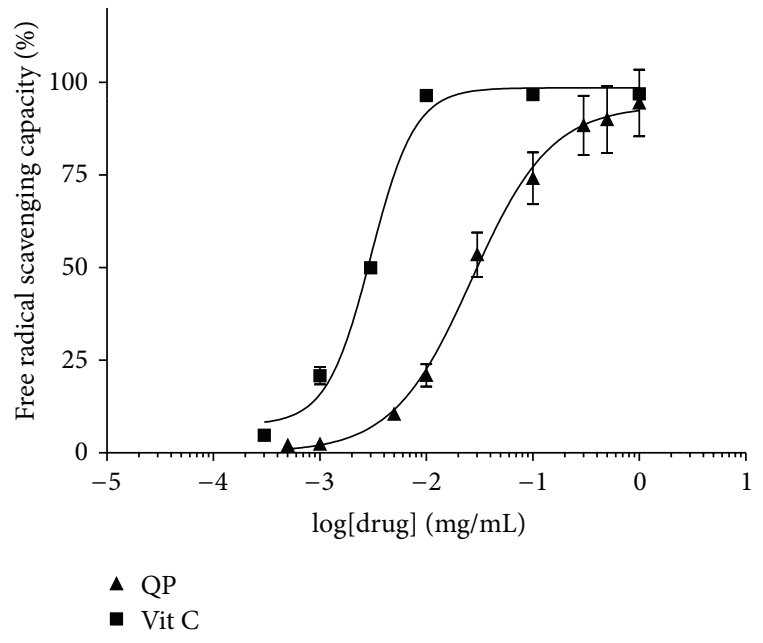

FIGURE 2: DPPH free radical scavenging capacity of QP water extract and Vitamin C (Vit C).

The concentration of 6-OHDA $(500 \mu \mathrm{M})$ was selected for the subsequent experiment for inducing apoptosis in PC12 cells.

Compared to the cells treated with 6-OHDA $(500 \mu \mathrm{M})$ alone, $2 \mathrm{~h}$ pretreatment of QP water extract could concentration-dependently $(0.03 \mathrm{mg} / \mathrm{mL}: 37.27 \pm 7.10 \%$, $P>0.05 ; 0.1 \mathrm{mg} / \mathrm{mL}: 54.30 \pm 4.79 \%, P<0.05 ; 0.3 \mathrm{mg} / \mathrm{mL}$ : $65.89 \pm 6.56 \%, P<0.001 ; 0.5 \mathrm{mg} / \mathrm{mL}: 72.10 \pm 1.44 \%$, $P<0.001 ; 1 \mathrm{mg} / \mathrm{mL}: 60.08 \pm 5.04 \%, P<0.001)$ improve cell viability in PC12 cells challenged with 6-OHDA $(500 \mu \mathrm{M})$ (Figure 3(b)). It was found that QP water extract $(0.5 \mathrm{mg} / \mathrm{mL})$ could provide the highest protection on the PC12 cells.

\subsection{QP Water Extract Reduces the Level of Intracellular ROS} in PC12 Cells Caused by 6-OHDA. As free radical scavenging capacity plays an important role in antioxidants which has the potential to protect the cells against oxidative stress-induced apoptosis, the measurement of intracellular ROS was used in this study to evaluate the effects of QP water extract on the changes of intracellular ROS level or the oxidative stress caused by 6-OHDA in PC12 cells. As shown in Figure 4, pretreatment with $0.5 \mathrm{mg} / \mathrm{mL}$ QP water extract could reverse the increase of intracellular ROS caused by 6-OHDA in PC12 cells to a certain level.

3.5. QP Water Extract Decreases the Apoptosis Induced by 6OHDA in PC12 Cells. Nucleus staining assay with Hoechst 33342 was taken to evaluate the morphological changes, which indicated apoptosis in PC12 cells. After observing cells under the fluorescence microscope $(\times 400$ magnification), compared with the morphological character in control group, the group treated with 6-OHDA $(500 \mu \mathrm{M}, 2 \mathrm{~h})$ exhibited the symptom of apoptosis, including shrinkage of nuclei and condensation of chromatin appearance of a few apoptotic bodies and less number of cells (Figure 5). In contrast, cells pretreated with QP water extract $(0.5 \mathrm{mg} / \mathrm{mL}$, $2 \mathrm{~h}$ ) showed less signs of apoptosis (Figure 5). Additionally, flow cytometry was used to further assess the apoptosis of PC12 cells through the measurement of mitochondrial membrane potential. As shown in Figure 6(a), pretreatment with QP water extract $(0.5 \mathrm{mg} / \mathrm{mL}, 2 \mathrm{~h})$ could reverse the PC12 mitochondrial membrane dysfunction induced by 6OHDA $(500 \mu \mathrm{M}, 4 \mathrm{~h})$ (Figure 6(b)).

3.6. QP Water Extract Attenuates 6-OHDA-Induced Apoptosis in PC12 Cells by Inhibiting ERK Pathway. To determine whether the ERK (extracellular signal-regulated kinases) pathway is involved in 6-OHDA induced apoptosis in PC12 cells, PD98059, a specific inhibitor of MEK, was used to pretreat PC12 cells for $2 \mathrm{~h}$ before exposure to 6-OHDA. 6OHDA-induced cell apoptosis was the most significantly suppressed by $50 \mu \mathrm{M}$ PD $98059(74.65 \pm 8.61 \%, P<0.001)$, compared with those treated with $500 \mu \mathrm{M}$ 6-OHDA alone (Figure 7(a)).

In addition, to prove whether 6-OHDA-induced apoptosis in PC12 cell is reversed by QP water extract through inhibiting the phosphorylation of ERK pathway, the levels of phospho-MEK and phospho-ERK are determined using Western blot assay. As shown in Figure 7(b), the level of phospho-ERK increased sharply to a peak $15 \mathrm{~min}$ 


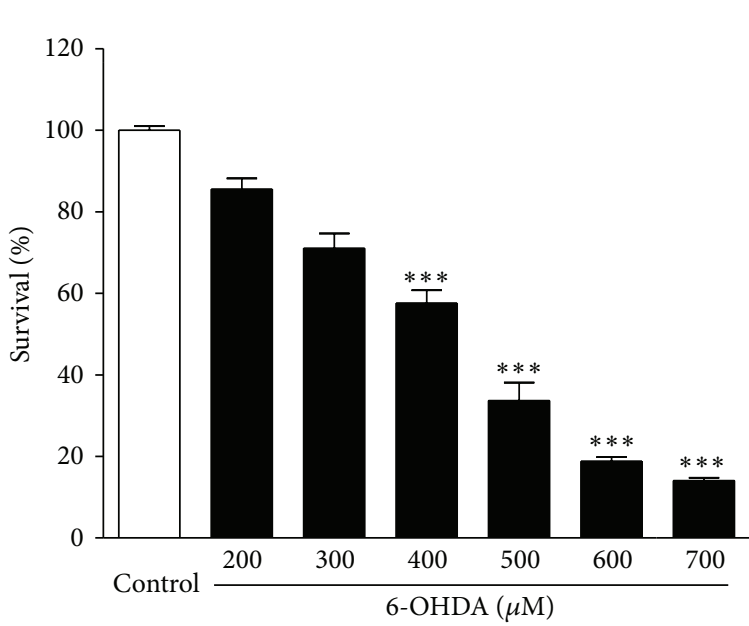

(a)

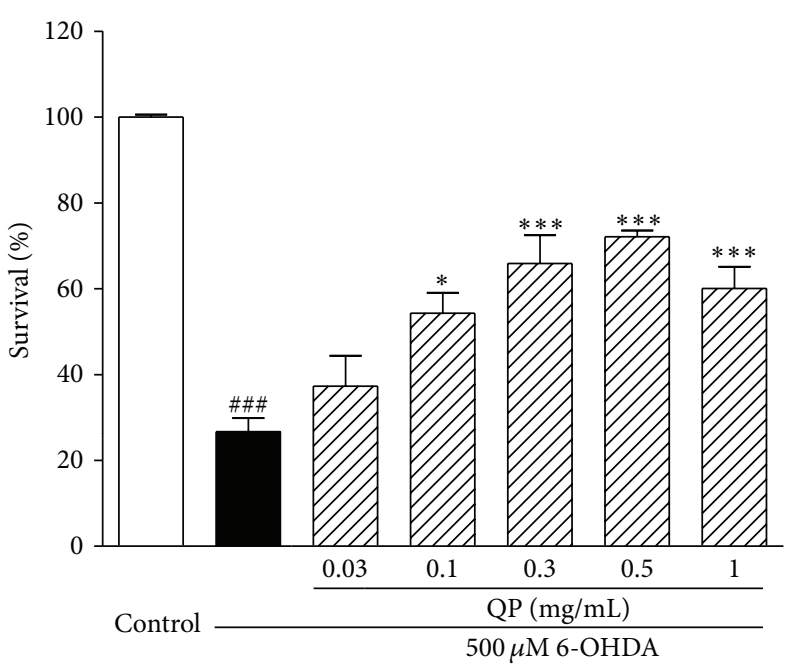

(b)

FIGURE 3: Examination of cytotoxicity of 6-OHDA and the effects of QP water extract on PC12 cells. (a) Cells were treated with different concentrations $(200,300,400,500,600$, or $700 \mu \mathrm{M})$ of 6 -OHDA for $6 \mathrm{~h}$. Data were expressed as the means \pm SEM of three separate experiments; ${ }^{* * *} P<0.001$ versus control. (b) PC12 cells were pretreated with QP water extract $(0.03,0.1,0.3,0.5$, or $1 \mathrm{mg} / \mathrm{mL}, 2 \mathrm{~h})$ before challenging with 6-OHDA $(500 \mu \mathrm{M}, 6 \mathrm{~h})$. Data were expressed as the means \pm SEM of three separate experiments; ${ }^{\# \#} P<0.001$ versus control and ${ }^{*} P<0.05$ and ${ }^{* * *} P<0.001$ versus 6 -OHDA alone group.

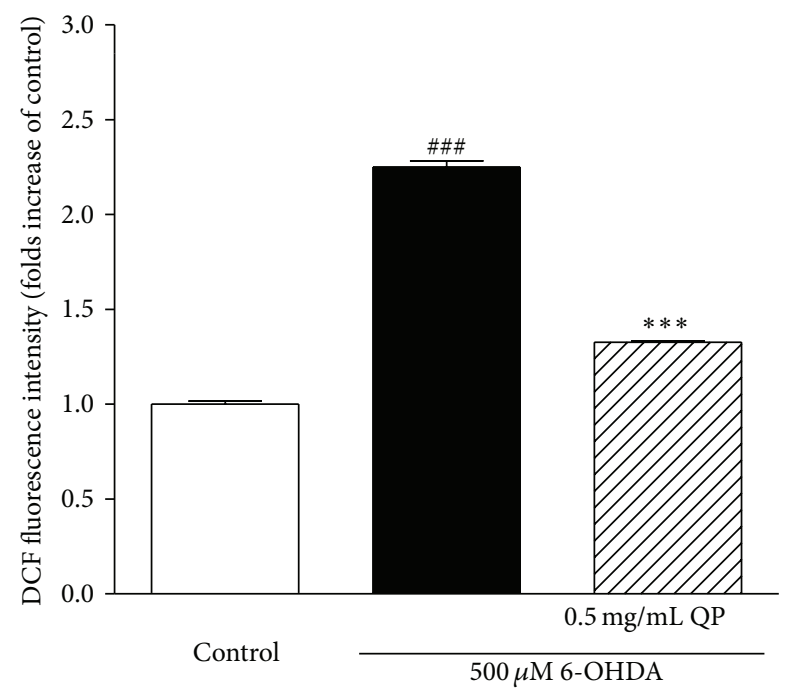

Figure 4: The effects of QP water extract on the changes of intracellular ROS caused by 6-OHDA. The PC12 cells were subjected to DCFH-DA $(20 \mu \mathrm{M})$ for $1 \mathrm{~h}$ followed by $2 \mathrm{~h}$ pretreatment with QP water extract $(0.5 \mathrm{mg} / \mathrm{mL})$, and then the PC12 cells were exposed to $500 \mu \mathrm{M} 6$-OHDA for $2 \mathrm{~h}$ before detection of DCF fluorescent intensities. Data were expressed as fold increases of control with means \pm SEM of three separate experiments; ${ }^{\# \#} P<0.001$ versus control and ${ }^{* * *} P<0.01$ versus 6 -OHDA alone group.

after exposure to $500 \mu \mathrm{M}$ 6-OHDA, therefore, we selected to collect the protein at $15 \mathrm{~min}$. It can be seen from the Figures 7(b) and 7(c) that pretreatment with QP water extract $(0.5 \mathrm{mg} / \mathrm{mL}, 2 \mathrm{~h})$ could significantly prevent the increase of phospho-MEK and phospho-ERK in $\mathrm{PC1} 2$ cells, resulting from oxidative stress caused by 6-OHDA.
3.7. QP Water Extract Reverses the 6-OHDA-Induced Suppression of PI3-K/Akt/Gsk3 $\beta$ Pathway in PC12 Cells. To verify that whether PI3-K (phosphatidylinositide-3'-OH kinase)/Akt (serine-threonine kinase c-Akt, also known as protein kinase B)/GSK3 $\beta$ (glycogen synthase kinse 3- $\beta$ ) pathway is involved in the protective effect of QP water extract on PC12 cells, LY294002 and SB415286, which are specific inhibitors of PI3$\mathrm{K}$ and GSK3, were used. As shown in Figures 8(a) and 8(b), LY294002 $(30 \mu \mathrm{M})$ had abolished the protective effect of QP water extract on PC12 cells to a certain level (54.12 $\pm 1.03 \%$, $P<0.001)$ while SB415286 $(30 \mu \mathrm{M})$ had shown the protective effects on 6-OHDA-induced death of PC12 cells (72.46 \pm $3.86 \%, P<0.001)$.

Moreover, the effects of QP water extract on the phophorylayed level of PI3-K/Akt/GSK3 $\beta$ were also checked by Western Blot assay. As shown in Figures 8(c) and 8(d), the level of phospho-PI3-K/Akt/GSK3 $\beta$ had decreased remarkably after exposure to $500 \mu \mathrm{M} 6$-OHDA for $60 \mathrm{~min}$. However, the inhibition of the phosphorylation could be reversed by pretreatment with QP water extract $(0.5 \mathrm{mg} / \mathrm{mL}, 2 \mathrm{~h})$ and the protective effect could be abolished by LY294002 at the same time.

\section{Discussion}

ROS is known as the reactive molecules, including oxygen radicals such as hydroperoxyl and superoxide radical and nonradical derivatives of oxygen such as hydrogen peroxide [13]. Overproduction of such kind of free radical may bring about oxidative damage to biomolecules and eventually lead to chronic diseases [14]. In neurodegenerative diseases, such as Alzheimer's disease (AD) and Parkinson's disease (PD), ROS does play a nonnegligible role [5]. It has been reported 


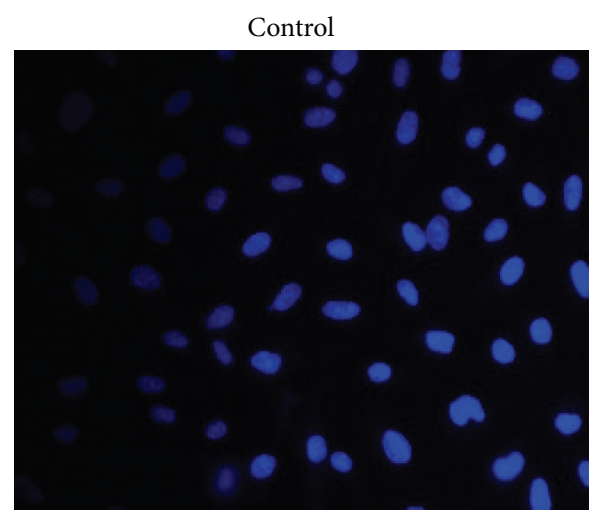

(a)

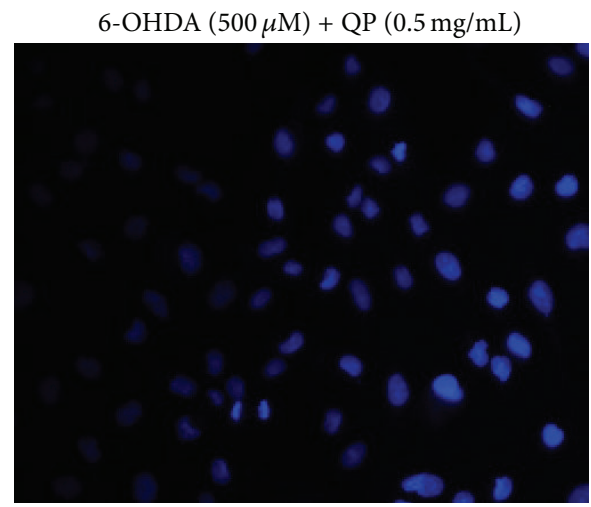

(c)

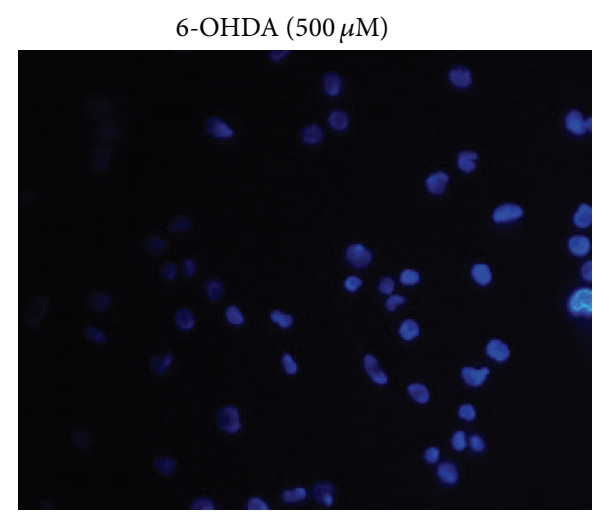

(b)

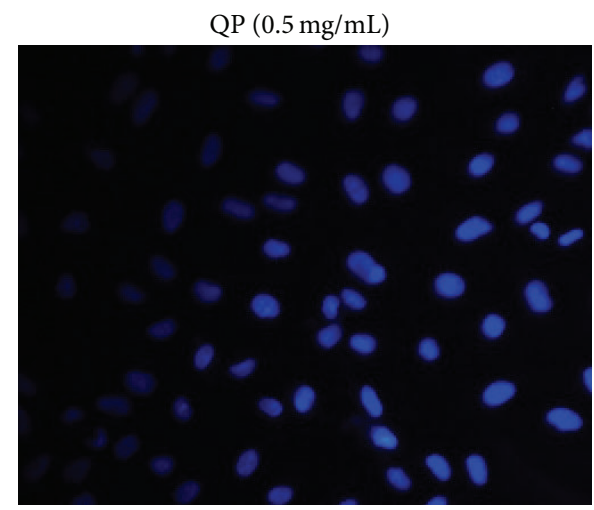

(d)

FIGURE 5: PC12 cells treated with different agents before Hoechst staining under the detection of 400x fluorescence microscope.

that both endogenous and exogenous ROS increases and/or the impairment of antioxidant defense systems could result in enhanced oxidative stress and cell apoptosis [15].

In the present study, both DPPH scavenging activity and total phenolic content were used to evaluate the antioxidant properties of QP water extract against ROS. As shown in the results, QP water extract scavenged the free radicals produced by $\mathrm{DPPH}$ solution in a concentration-dependent manner with $\mathrm{SC}_{50}$ equal to $0.15 \mathrm{mg} / \mathrm{mL}$ and its free radical scavenging ability is relatively lower than those of some common Chinese herbs, for example, Cratoxylum cochinchinense, Cortex magnoliae officinalis, Psoralea corylifolia L., Curculigo orchioides Gaertn., and Glycyrrhiza uralensis Fisch. [5]. In the current study, total phenolic contents were also measured using Folin-Ciocalteu Method [16]. The total phenolic content of QP water extract was found to be $200.78 \pm 2.65 \mathrm{mg} \mathrm{GAE} / \mathrm{g}$, which is relatively higher than those of some water extracts from Baccharis genistelloides, Physalis alkekengi, Taraxacum mongolicun, and so forth [17].

6-OHDA, a hydroxylated dopamine analogue, can be taken up by the dopamine transporter and causes the release of free radicals that exert toxicity in neuronal tissues [18]. It has been extensively used as an inducer of oxidative stress on neuronal cells. To mimic the disease situation, PC12 cells were exposed to 6-OHDA to induce cell damage. The current results demonstrated that PC12 cells pretreated with QP water extract $(0.5 \mathrm{mg} / \mathrm{mL}, 2 \mathrm{~h})$ could significantly improve the cell viability (Figure 3(b)). It is found that the protective effect of QP water extract on PC12 cells may result from reducing intracellular ROS caused by 6-OHDA (Figure 4). The antiapoptotic effect of QP water extract was further confirmed by morphological observations (Figure 5). With the help of Hoechst 33342 staining, it was found that cells pretreated with QP water extract $(0.5 \mathrm{mg} / \mathrm{mL}, 2 \mathrm{~h})$ before challenging with 6OHDA $(500 \mu \mathrm{M}, 6 \mathrm{~h})$ showed less symptoms of apoptosis as compared with those exposed to 6-OHDA alone.

Mitochondrion is one of the main targets of ROS and its dysfunction in the mitophagy pathway can lead to several neurodegenerative disorders [19, 20]. Using CCCP, which usually acts as an ionophore, could quickly and universally dissipate the proton gradient of the mitochondrial inner membrane [20]. It was used in this study to confirm that JC-1 response is sensitive to changes in membrane potential. QP water extract could significantly reverse the depolarization level of mitochondrial membrane caused by 6-OHDA (Figures 6(a) and 6(b)).

It has been verified in multiple studies that apoptosis is among the main causes that lead to oxidative stressinduced neurodegenerative disease [10]. Among the signal transduction pathways leading to apoptosis, ERKs are one of the well-characterized pathways [21-24]. Moreover, it had received much more attention these years because of its high frequency of KRAS and BRAF mutations identified in certain human cancers and the critical role this pathway 

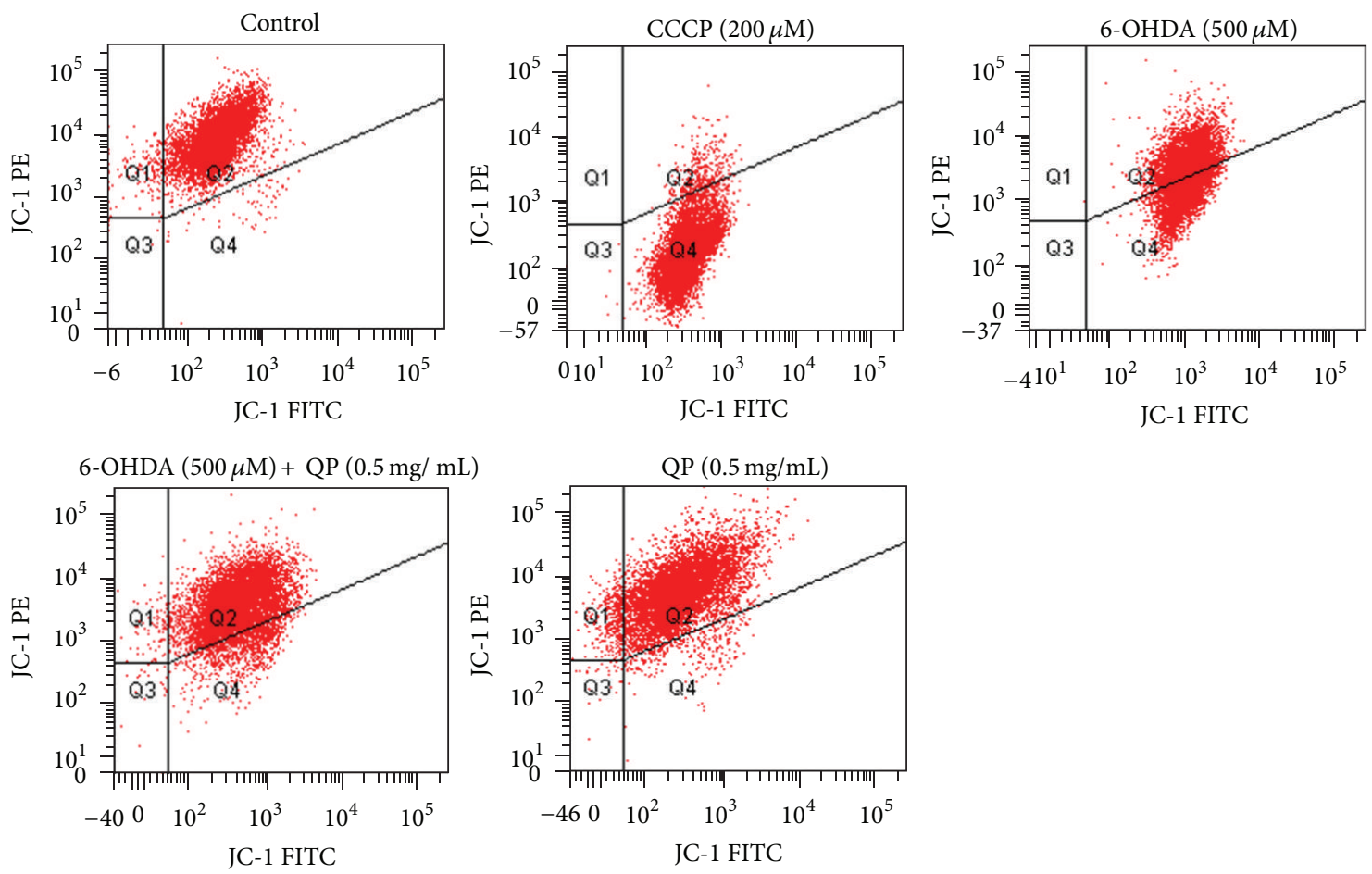

(a)

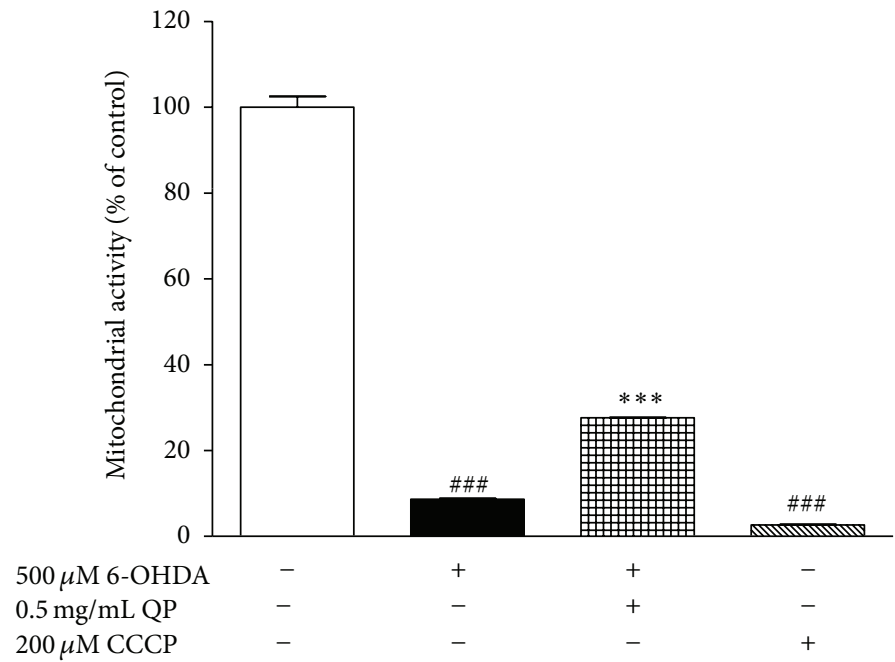

(b)

FIGURE 6: QP water extract attenuated 6-OHDA-induced apoptosis in PC12 cells. (a) Effects of QP water extract (0.5 mg/mL) on the changes of mitochondrial membrane potential induced by 6-OHDA $(500 \mu \mathrm{M})$. (b) Statistical analysis of the red/green fluorescence intensity ratio, namely mitochondrial membrane potential, expressed as the percentage of control. Data were expressed as means \pm SEM of three separate experiments; ${ }^{\# \# \#} P<0.001$ versus control and ${ }^{* * *} P<0.001$ versus 6 -OHDA alone group.

plays in promoting cell survival [25]. Along the cascade, the members of the each echelon, from the Raf family to p90 ribosomal S6 kinase (RSK), are activated one by one [26], among which the phosphorylation of mitogen-activated protein kinases (MAPKs) plays a dominant role [27]. And the phosphorylated level of ERK $1 / 2$ and its upstream signal MEK 1/2 had been proved earlier that it could promote 6OHDA induced cell damages in PC12 cells $[16,28]$. It is shown with the treatment of PD98059 that ERK pathway was involved in 6-OHDA-induced apoptosis of PC12 cells. What is more, the level of phosphorylation of ERK $1 / 2$ and MEK $1 / 2$ is attenuated with $2 \mathrm{~h}$ pretreatment of QP water extract, which indicated that QP water extract did protect the PC12 cells from apoptosis by eliminating the increase in phosphoERK induced by 6-OHDA.

Apart from MEK/ERK pathway, the PI3-K/Akt/GSK3 $\beta$ pathway may be another vital target to improve cells survival [29]. To be specific, PI3-K/Akt are well defined as mediators 


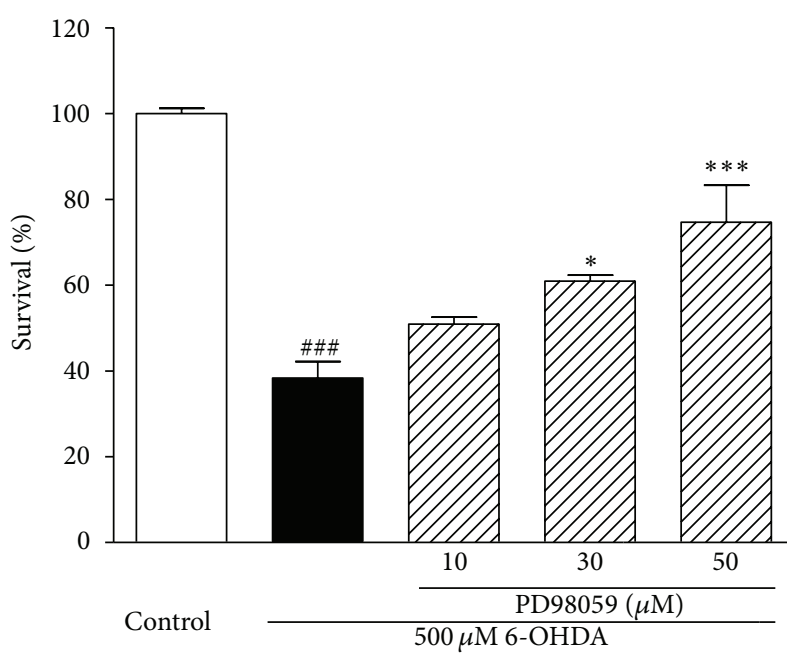

(a)

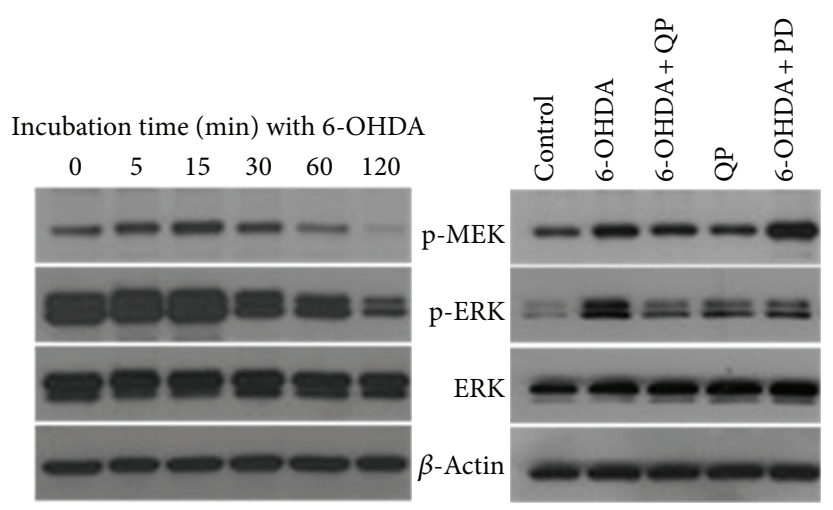

(b)

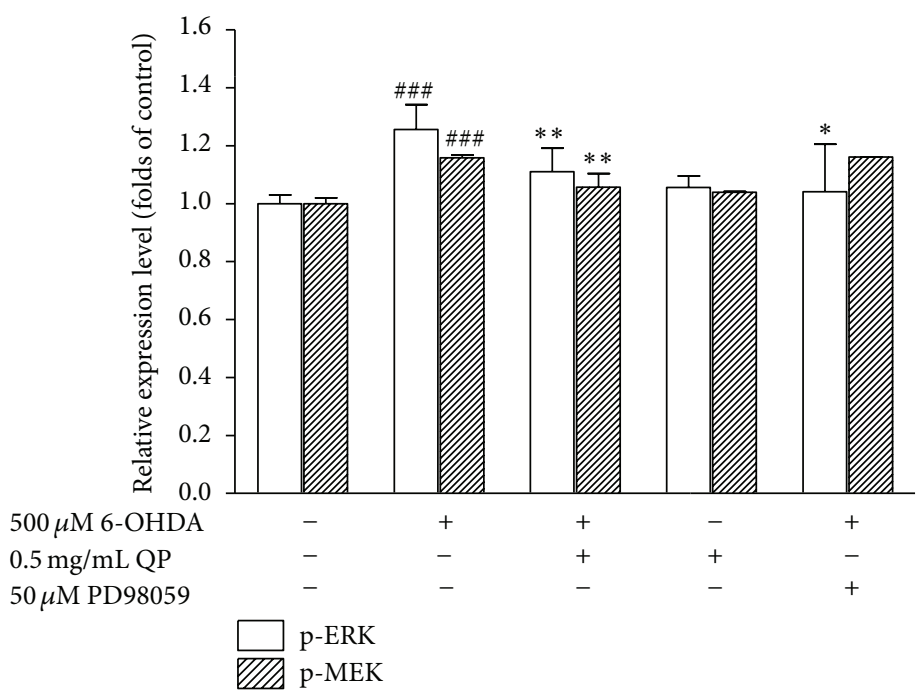

(c)

FIGURE 7: QP water extract exerted neuroprotective effect on 6-OHDA treated PC12 cells through inhibiting ERK pathway. (a) Pretreatment of PD98059 for $2 \mathrm{~h}$ prevented 6-OHDA-induced cell apoptosis in a concentration-dependent manner. Data were expressed as means \pm SEM of three separate experiments, with ${ }^{\# \# \# ~} P<0.001$ versus control and ${ }^{* * *} P<0.001$ and ${ }^{*} P<0.05$ versus 6-OHDA alone group. (b) The increase of phospho-ERK and phospho-MEK caused by 6-OHDA $(500 \mu \mathrm{M})$ at $15 \mathrm{~min}$ was reversed by pretreatment with QP water extract $(0.5 \mathrm{mg} / \mathrm{mL}$, $2 \mathrm{~h})$. (c) The band from three independent experiments were quantified by densitometry and shown as group. Calculated as fold of control, data were expressed as means \pm SEM of three separate experiments, ${ }^{\# \# \#} P<0.001$ versus control and ${ }^{* *} P<0.01$ and ${ }^{* *} P<0.05$ versus 6 OHDA alone group.

for cell survival, activated by some peptide factors including the neurotrophins and growth factors [30]. By using of specific PI3-K inhibitor LY294002, the effect of QP water extract was blocked (Figures $8(\mathrm{a})-8(\mathrm{~d})$ ), which indicating $\mathrm{PI} 3-\mathrm{K} / \mathrm{Akt}$ is involved in the protective effect of QP water extract. On the other hand, GSK3 $\beta$, another regulator related to cell apoptosis, was defined as the downstream kinase of PI3-K/Akt in some of the primary studies $[31,32]$. The activity of GSK $3 \beta$ is positively regulated by $6-\mathrm{OHDA}$ at tyrosine 216 (Tyr216) but negatively at serine 9 (ser9) by phosphorylation [33]. Through the use of GSK3 $\beta$ inhibitor SB415286, we had verified that GSK3 $\beta$ is involved in the 6-OHDA-induced
PC12 cell damage (Figure 8(b)). Regulated by PI3-K/Akt, the inactivation of downstream GSK $3 \beta$ through phosphorylation at ser9 by QP water extract can also explain its protective effect on PC12 cells. As a result, we proposed that PI3$\mathrm{K} / \mathrm{Akt} / \mathrm{GSK} 3 \beta$ pathway is involved in this model. Besides, it was demonstrated that the reduction in the level of phosphorylated PI3-K/Akt/GSK3 $\beta$ was reversed by pretreatment with QP water extract $(0.5 \mathrm{mg} / \mathrm{mL}, 2 \mathrm{~h})$, which indicated that it could protect PC12 cells from 6-OHDA induced apoptosis by reversing the inhibition of PI3-K/Akt/GSK3 $\beta$ pathway.

Although we demonstrated that QP water extract has relatively high neuroprotective capacity using in vitro cell 


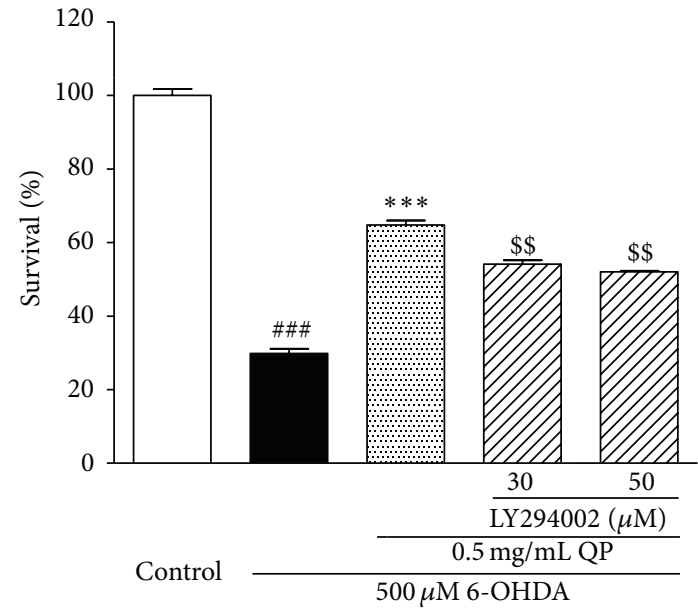

(a)

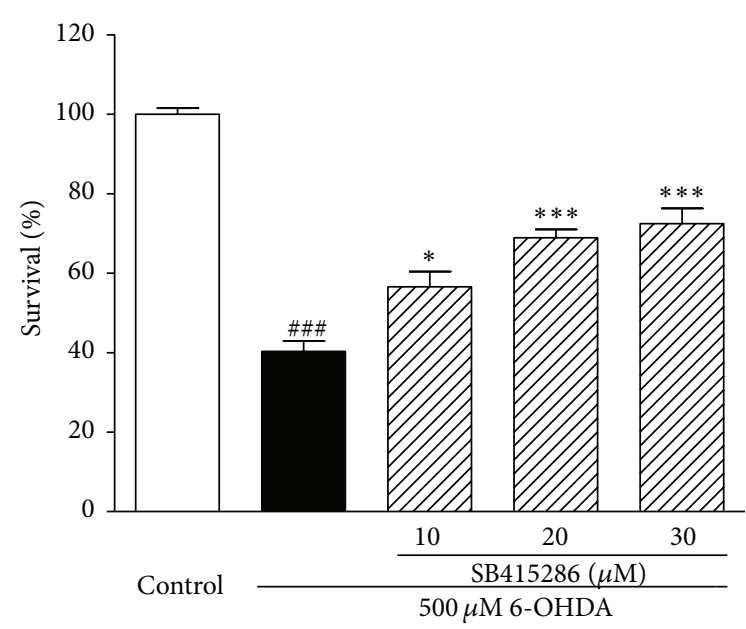

(b)
Incubation time (min) with 6-OHDA

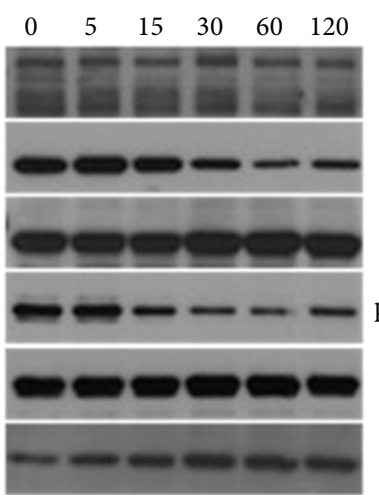

(c)

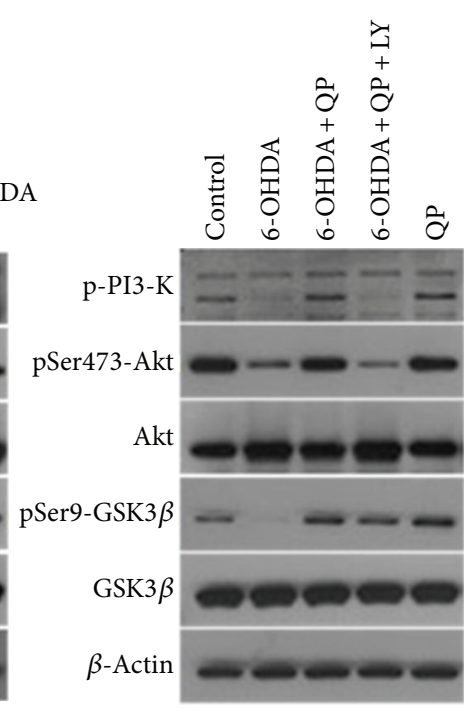

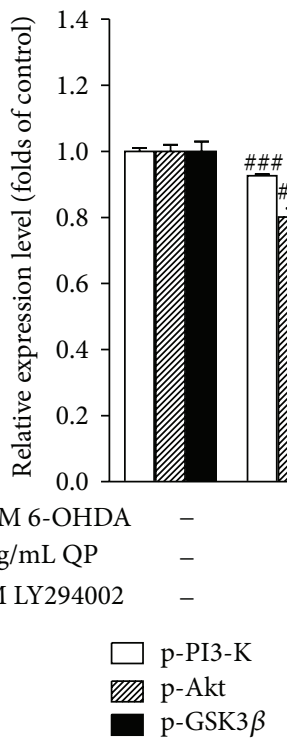

(d)

FIGURE 8: QP water extract exerted neuroprotective effect on 6-OHDA treated PC12 cells through activating PI3-K/Akt/GSK3 $\beta$ pathway. ((a), (b)) The neuroprotective effect of QP water extract on PC12 cells against 6-OHDA can be reversed by LY294002 and in a concentrationdependent manner. PC12 cells were exposed to $500 \mu \mathrm{M} 6-\mathrm{OHDA}$ at $2 \mathrm{~h}$ after pretreatment with both QP water extract $(0.5 \mathrm{mg} / \mathrm{mL})$ and LY294002 and SB415286 at different concentrations as indicated. Data, expressed as percentage of control, were expressed as means \pm SEM of three separate experiments; ${ }^{\# \# \#} P<0.001$ versus control, ${ }^{* * *} P<0.01$ and ${ }^{*} P<0.05$ versus 6 -OHDA alone group, and ${ }^{\$ \$} P<0.01$ versus 6-OHDA with pretreatment of QP water extract group. (c) QP water extract had reversed the decline of phospho-PI3-K, phospho-AKT, and phospho-GSK3 $\beta$ caused by 6-OHDA to a certain level ${ }^{\$ \$} P<0.001$ and ${ }^{\$ \$} P<0.01$ versus 6-OHDA with QP water extract pretreatment group. PC12 cells were pretreated with QP water extract $(0.5 \mathrm{mg} / \mathrm{mL}, 2 \mathrm{~h})$ and then exposed to 6-OHDA (500 $\mu \mathrm{M})$ for $60 \mathrm{~min}$. (d) The bands from three independent experiments were quantified by densitometry and shown as group. Calculated as fold of control, data were expressed as means \pm SEM of three separate experiments; ${ }^{\# \# \#} P<0.001$ versus control, ${ }^{* * *} P<0.001$ versus 6 -OHDA alone group, and ${ }^{\$ \$} P<0.001$ and $\$ P<0.01$ versus 6-OHDA with QP water extract pretreatment group.

model, further studies are still needed to determine QP's neuroprotective effects against intracellular ROS-induced oxidative stress. Upregulation of antioxidant enzymes such as SOD, GPx, and CAT is one of the major defense systems to handle oxidative stress [34]. Targeting these enzymes could be one of the underlying mechanisms of QP water extract's effects. Further study on this area may provide more insights on the mechanisms of QP.
Due to the high level of oxygen consumption of brain, the nervous system is usually more vulnerable to the damage of homeostasis between the production of ROS and defense mechanisms [35]. Normal dopaminergic transmission plays an important role in regulating neuronal functions and previous studies had shown that there may be a correlation ship between the oxidative stress, as well as ROS induced apoptosis, and dopaminergic alteration [36]. On the other 
hand, in PD patients, selective vulnerability of dopaminergic neuron is found and dopamine (DA) autooxidation together with its metabolism by monoamine oxidase $B$ would produce 6-OHDA as well as dopamine quinones, which could generate ROS [37]. In the present study, by using of 6-OHDA and PC12 cells, the main pathology of PD was mimicked in vitro, and $\mathrm{QP}$ water extract was verified to have the capacity of scavenging ROS produced by 6-OHDA, which could provide evidence of its potential in developing innovated agent for treatment of PD.

Since there was no study demonstrating that QP water extract has neuroprotective capacity, it is still unknown that whether it can cross brain barrier. We had found that there are four main constituents in QP water extract through HPLC, including exculin hydrate, fraxin, esculetin, and flaxetin. According to their chemical property, exculin and fraxin have high polarity while esculetin and flaxetin have relatively low polarity, which make them easier to cross the brain barrier. In particular, there are previous studies showing that esculetin and flaxetin could prevent the neurotoxicity caused by agents other than 6-OHDA and they were reported to be easy to cross blood-brain barrier [38, 39]. However, further studies using in vivo animal model or in vitro tissue culture are needed to clarify whether it QP water extract, a TCM with complex constituents, can cross the brain barrier as whole.

\section{Conclusion}

In summary, QP water extract was demonstrated to have strong antioxidant property in $\mathrm{DPPH}$ assay with $\mathrm{SC}_{50}=$ $0.15 \mathrm{mg} / \mathrm{mL}$. Total phenolic content of QP water extract was found to be $200.78 \pm 2.65 \mathrm{mg} \mathrm{GAE} / \mathrm{g}$. Additionally, QP water extract $(0.5 \mathrm{mg} / \mathrm{mL})$ could remarkably increase $(P<$ $0.001)$ the viability of PC12 cells treated with 6-OHDA as compared with the vehicle and reverse-increase intracellular ROS level at the same time. The antiapoptotic effects of QP water extract was shown in Hoechst staining assay and flow cytometry analysis. The protective effect of QP water extract was found to be via inhibiting MEK/ERK pathway and reversing PI3-K/Akt/GSK3 $\beta$ pathway. The current results suggest that QP might be a potential candidate for preventing the development of neurodegenerative diseases, such as PD.

\section{Abbreviations}

PD: $\quad$ Parkinson's disease

DMSO: Dimethyl sulfoxide

DPPH: 1,1-Diphenyl-2-picrylhydrazyl

ROS: $\quad$ Reactive oxygen species

SR\%: $\quad$ Free radical scavenging capacity

$\mathrm{SC}_{50}$ : Concentration of sample that contributes $50 \%$ of scavenging capacity

QP: $\quad$ Cortex Fraxini (Qingpi)

6-OHDA: 6-Hydroxydopamine

PC12 cells: Rat pheochromocytoma cells

TCM: Traditional chinese medicine

MTT: 3-(4,5-Dimethylthiazol-2yl)-2,5diphenyltetrazolium brmide.

\section{Conflict of Interests}

The authors declare that they have no conflict of interests.

\section{Acknowledgments}

This research was financially supported by the Department of Applied Biology and Chemical Technology, The Hong Kong Polytechnic University, National Basic Research Program (973) (Project code: 2012CB723506) and Shenzhen Key Laboratory Advancement Program (Project code: CXB201104220020A).

\section{References}

[1] C. J. Tang, S. W. Chan, W. T. Zhou, and S. Y. Liaw, "Collaboration between hospital physicians and nurses: an integrated literature review," International Nursing Review, vol. 60, no. 3, pp. 291-302, 2013.

[2] J. Ganz, N. Lev, E. Melamed, and D. Offen, "Cell replacement therapy for Parkinson's disease: how close are we to the clinic?" Expert Review of Neurotherapeutics, vol. 11, no. 9, pp. 1325-1339, 2011.

[3] J. Rodriguez-Pallares, J. A. Parga, A. Muñoz, P. Rey, M. J. Guerra, and J. L. Labandeira-Garcia, "Mechanism of 6hydroxydopamine neurotoxicity: the role of NADPH oxidase and microglial activation in 6-hydroxydopamine-induced degeneration of dopaminergic neurons," Journal of Neurochemistry, vol. 103, no. 1, pp. 145-156, 2007.

[4] S. Y. Tang, M. Whiteman, Z. F. Peng, A. Jenner, E. L. Yong, and B. Halliwell, "Characterization of antioxidant and antiglycation properties and isolation of active ingredients from traditional chinese medicines," Free Radical Biology and Medicine, vol. 36, no. 12, pp. 1575-1587, 2004.

[5] G. Paradies, G. Petrosillo, V. Paradies, and F. M. Ruggiero, "Mitochondrial dysfunction in brain aging: role of oxidative stress and cardiolipin," Neurochemistry International, vol. 58, no. 4, pp. 447-457, 2011.

[6] N. Simola, M. Morelli, and A. R. Carta, "The 6-hydroxydopamine model of Parkinson's disease," Neurotoxicity Research, vol. 11, no. 3-4, pp. 151-167, 2007.

[7] Chinese-Pharmacopoeia-Commission, Pharmacopoeia of the People's Republic of China, Chinese Medical Science Press, Beijing, China, 2010.

[8] L. Zhou, J. Kang, L. Fan et al., "Simultaneous analysis of coumarins and secoiridoids in Cortex Fraxini by high-performance liquid chromatography-diode array detection-electrospray ionization tandem mass spectrometry," Journal of Pharmaceutical and Biomedical Analysis, vol. 47, no. 1, pp. 39-46, 2008.

[9] S. Von Kruedener, W. Schneider, and E. F. Elstner, "Effects of extracts from Populus tremula L., Solidago virgaurea L. and Fraxinus excelsior L. on various myeloperoxidase systems," Arzneimittel-Forschung, vol. 46, no. 8, pp. 809-814, 1996.

[10] G. Manning, D. B. Whyte, R. Martinez, T. Hunter, and S. Sudarsanam, "The protein kinase complement of the human genome," Science, vol. 298, no. 5600, pp. 1912-1934, 2002.

[11] F. Li, J.-H. Wu, Q.-H. Wang et al., "Gui-ling-gao, a traditional Chinese functional food, prevents oxidative stress-induced apoptosis in H9c2 cardiomyocytes," Food \& Function, vol. 4, no. 5, pp. 745-753, 2013.

[12] C. P. LeBel, H. Ischiropoulos, and S. C. Bondy, "Evaluation of the probe $2^{\prime}, 7^{\prime}$-dichlorofluorescin as an indicator of reactive oxygen 
species formation and oxidative stress," Chemical Research in Toxicology, vol. 5, no. 2, pp. 227-231, 1992.

[13] G. Burton and D. D. M. Wayner, "Free-radicals in biology and medicine," Nature, vol. 318, no. 6044, p. 322, 1985.

[14] Y. Cai, Q. Luo, M. Sun, and H. Corke, "Antioxidant activity and phenolic compounds of 112 traditional Chinese medicinal plants associated with anticancer," Life Sciences, vol. 74, no. 17, pp. 2157-2184, 2004.

[15] C. Behl and B. Moosmann, "Antioxidant neuroprotection in Alzheimer's disease as preventive and therapeutic approach," Free Radical Biology \& Medicine, vol. 33, no. 2, pp. 182-191, 2002.

[16] L. Conde de la Rosa, M. H. Schoemaker, T. E. Vrenken et al., "Superoxide anions and hydrogen peroxide induce hepatocyte death by different mechanisms: Involvement of JNK and ERK MAP kinases," Journal of Hepatology, vol. 44, no. 5, pp. 918-929, 2006.

[17] P. Diaz, S. C. Jeong, S. Lee, C. Khoo, and S. R. Koyyalamudi, "Antioxidant and anti-inflammatory activities of selected medicinal plants and fungi containing phenolic and flavonoid compounds," Chinese Medicine, vol. 7, article 26, 2012.

[18] G. Cohen and R. E. Heikkila, "The generation of hydrogen peroxide, superoxide radical, and hydroxyl radical by 6 hydroxydopamine, dialuric acid, and related cytotoxic agents," The Journal of Biological Chemistry, vol. 249, no. 8, pp. 2447-2452, 1974.

[19] J. D. Ly, D. R. Grubb, and A. Lawen, "The mitochondrial membrane potential $(\delta \psi \mathrm{m})$ in apoptosis; an update," Apoptosis, vol. 8, no. 2, pp. 115-128, 2003.

[20] Y. Wang, Y. Nartiss, B. Steipe, G. A. McQuibban, and P. K. Kim, "ROS-induced mitochondrial depolarization initiates PARK2/PARKIN-dependent mitochondrial degradation by autophagy," Autophagy, vol. 8, no. 10, pp. 1462-1476, 2012.

[21] A. Bonni, A. Brunet, A. E. West, S. R. Datta, M. A. Takasu, and M. E. Greenberg, "Cell survival promoted by the RasMAPK signaling pathway by transcription-dependent and independent mechanisms," Science, vol. 286, no. 5443, pp. 1358$1362,1999$.

[22] A. K. Howe, A. E. Aplin, and R. L. Juliano, "Anchoragedependent ERK signaling-mechanisms and consequences," Current Opinion in Genetics and Development, vol. 12, no. 1, pp. 30-35, 2002.

[23] A. Vinayagam, U. Stelzl, R. Foulle et al., "A directed protein interaction network for investigating intracellular signal transduction," Science Signaling, vol. 4, no. 189, 2011.

[24] Z. Xia, M. Dickens, J. Raingeaud, R. J. Davis, and M. E. Greenberg, "Opposing effects of ERK and JNK-p38 MAP kinases on apoptosis," Science, vol. 270, no. 5240, pp. 1326-1331, 1995.

[25] A. S. Little, K. Balmanno, M. J. Sale et al., "A correction to the research article titled: "amplification of the driving oncogene, KRAS or BRAF, underpins acquired resistance to MEK1/2 inhibitors in colorectal cancer cells" by A. S. Little, K. Balmanno, M. J. Sale, S. Newman, J. R. Dry, M. Hampson, P. A. W. Edwards, P. D. Smith, S. J. Cook," Science Signaling, vol. 4, no. 170, p. er2, 2011.

[26] G. M. Thomas and R. L. Huganir, "MAPK cascade signalling and synaptic plasticity," Nature Reviews Neuroscience, vol. 5, no. 3, pp. 173-183, 2004.

[27] P. Andreu-Pérez, R. Esteve-Puig, C. de Torre-Minguela et al., "Protein arginine methyltransferase 5 regulates ERK1/2 signal transduction amplitude and cell fate through CRAF," Science Signaling, vol. 4, no. 190, article ra58, 2011.
[28] J. A. McCubrey, L. S. Steelman, W. H. Chappell et al., "Roles of the Raf/MEK/ERK pathway in cell growth, malignant transformation and drug resistance," Biochimica et Biophysica ActaMolecular Cell Research, vol. 1773, no. 8, pp. 1263-1284, 2007.

[29] X.-Q. Tang, Y.-Y. Zhuang, L.-L. Fan et al., "Involvement of $\mathrm{K}_{A T P} / \mathrm{PI}_{3} \mathrm{~K} / \mathrm{AKT} / \mathrm{Bcl}-2$ pathway in hydrogen sulfide-induced neuroprotection against the toxicity of 1-methy-4-phenylpyridinium ion," Journal of Molecular Neuroscience, vol. 46, no. 2, pp. 442-449, 2012.

[30] S. R. Datta, H. Dudek, T. Xu et al., "Akt phosphorylation of BAD couples survival signals to the cell- intrinsic death machinery," Cell, vol. 91, no. 2, pp. 231-241, 1997.

[31] V. D. Nair and C. W. Olanow, "Differential modulation of akt/glycogen synthase kinase- $3 \beta$ pathway regulates apoptotic and cytoprotective signaling responses," Journal of Biological Chemistry, vol. 283, no. 22, pp. 15469-15478, 2008.

[32] L. Teng, Q. Meng, J. Lu et al., "Liquiritin modulates ERK and AKT/GSK3betadependent pathways to protect against glutamateinduced cell damage in differentiated PC12 cells," Molecular Medicine Reports, vol. 10, no. 2, pp. 818-824, 2014.

[33] G. Chen, K. A. Bower, C. Ma, S. Fang, C. J. Thiele, and J. Luo, "Glycogen synthase kinase $3 \beta$ (GSK3 $\beta$ ) mediates 6hydroxydopamine- induced neuronal death," The FASEB Journal, vol. 18, no. 10, p. 1162, 2004.

[34] M.-W. Hung, G. L. Tipoe, A. M.-S. Poon, R. J. Reiter, and M.L. Fung, "Protective effect of melatonin against hippocampal injury of rats with intermittent hypoxia," Journal of Pineal Research, vol. 44, no. 2, pp. 214-221, 2008.

[35] L. Lavie, "Oxidative stress-a unifying paradigm in obstructive sleep apnea and comorbidities," Progress in Cardiovascular Diseases, vol. 51, no. 4, pp. 303-312, 2009.

[36] L. P. Chandravanshi, R. K. Shukla, S. Sultana, A. B. Pant, and V. K. Khanna, "Early life arsenic exposure and brain dopaminergic alterations in rats," International Journal of Developmental Neuroscience, vol. 38, pp. 91-104, 2004.

[37] M. Shah, S. Rajagopalan, L. Xu et al., "The high-affinity D2/D3 agonist D512 protects PC12 cells from 6-OHDA-induced apoptotic cell death and rescues dopaminergic neurons in the MPTP mouse model of Parkinson's disease," Journal of Neurochemistry, vol. 10, pp. 1-12, 2014.

[38] M. F. Molina-Jiménez, M. I. Sánchez-Reus, D. Andres, M. Cascales, and J. Benedi, "Neuroprotective effect of fraxetin and myricetin against rotenone-induced apoptosis in neuroblastoma cells," Brain Research, vol. 1009, no. 1-2, pp. 9-16, 2004.

[39] S. R. Subramaniam and E. M. Ellis, "Neuroprotective effects of umbelliferone and esculetin in a mouse model of Parkinson's disease," Journal of Neuroscience Research, vol. 91, no. 3, pp. 453461, 2013. 


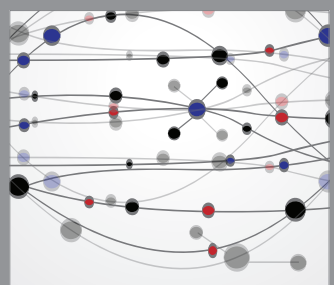

The Scientific World Journal
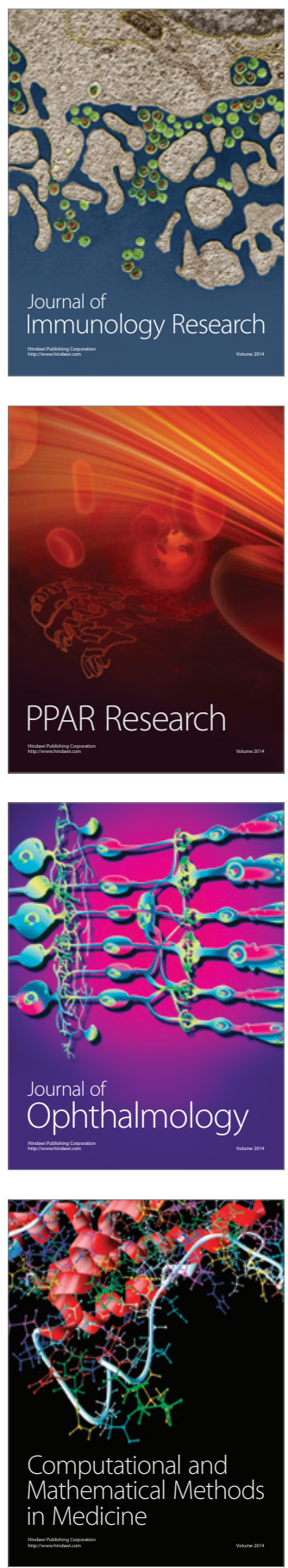

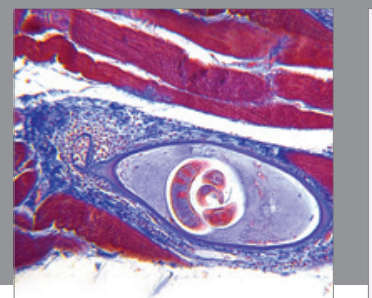

Gastroenterology

Research and Practice
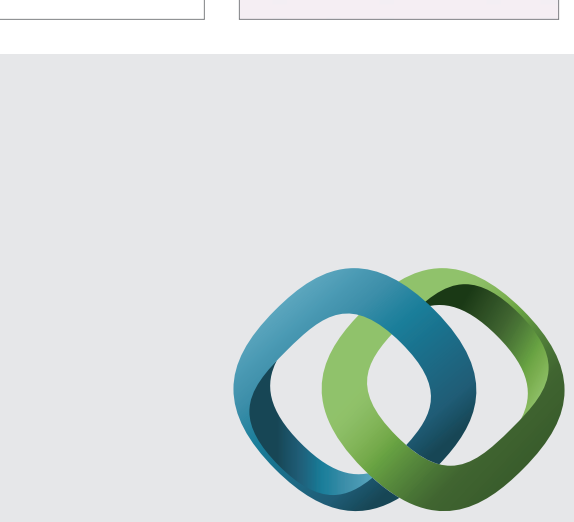

\section{Hindawi}

Submit your manuscripts at

http://www.hindawi.com
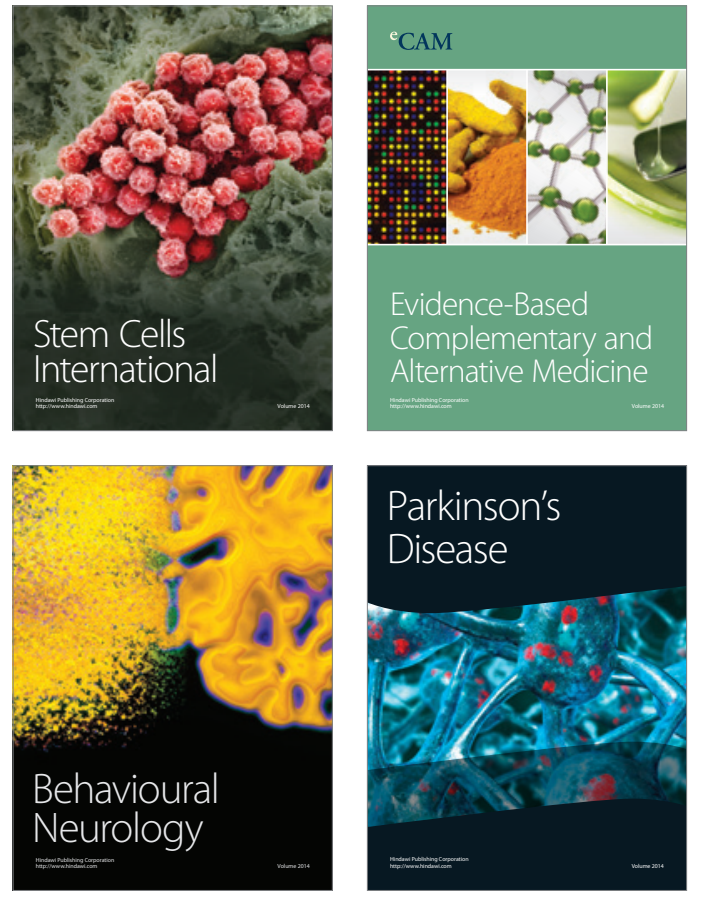
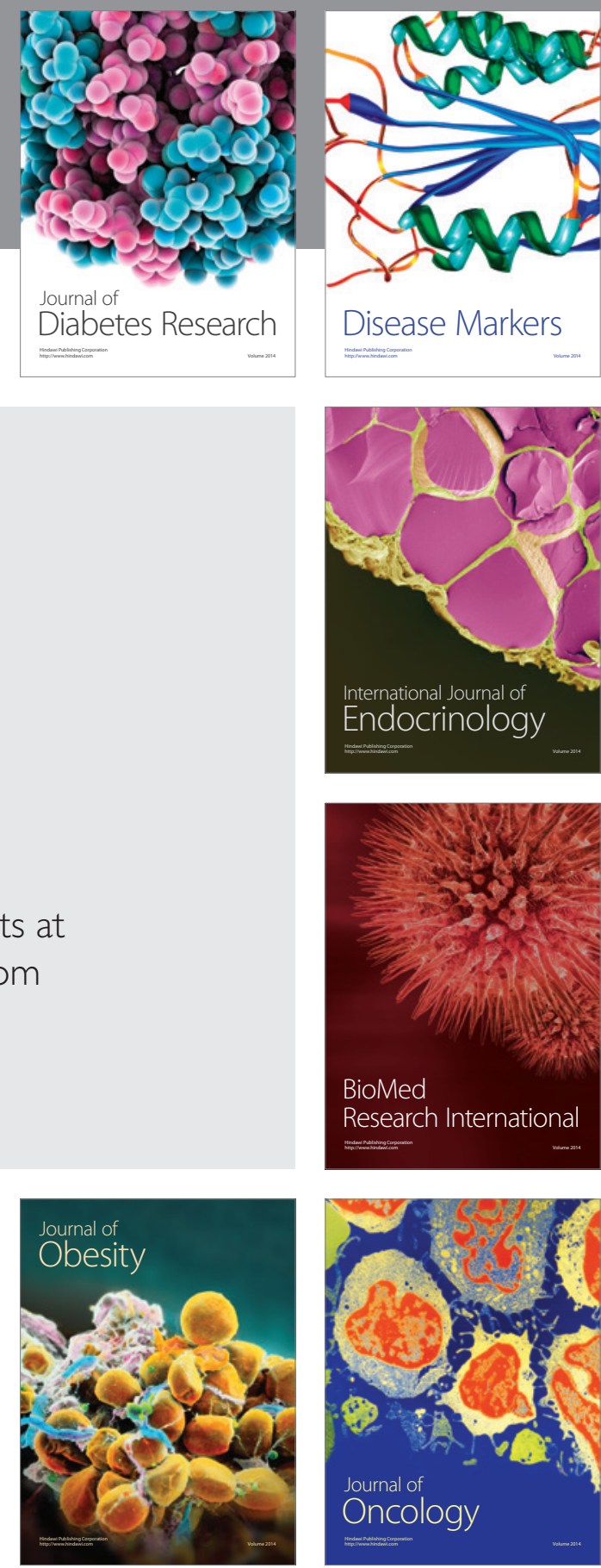

Disease Markers
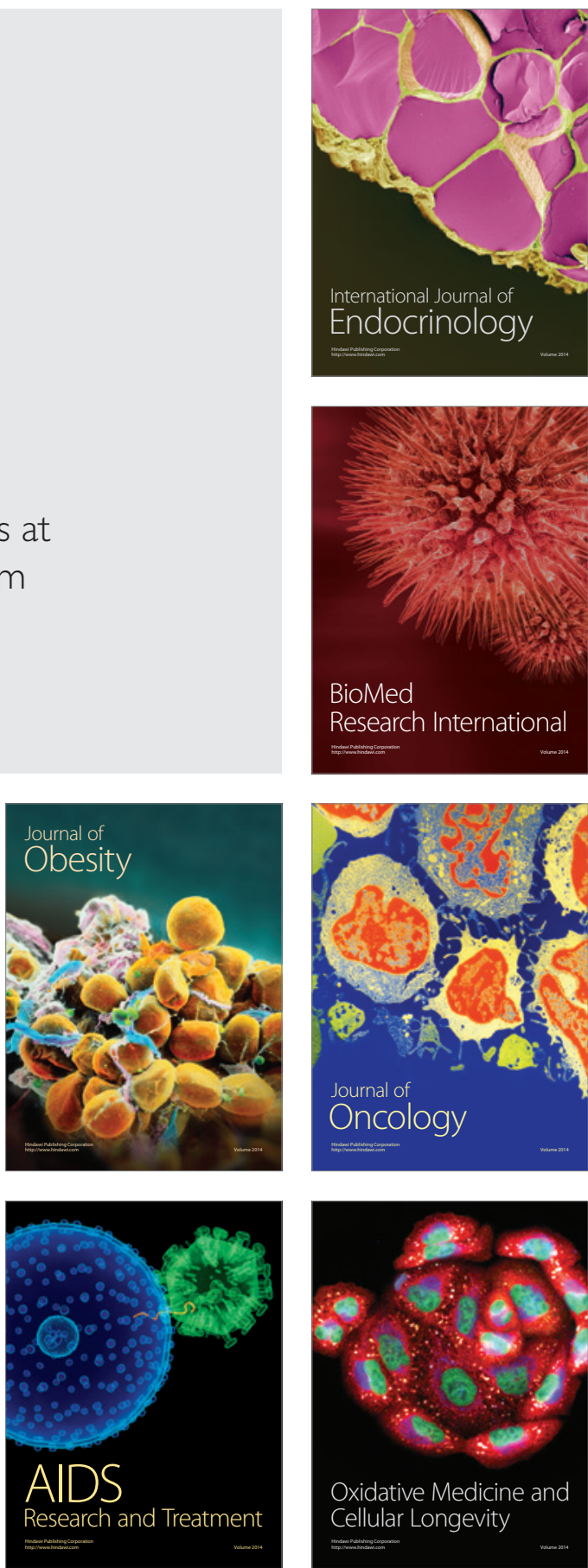